\title{
A ética e a lei em Azdak, de 0 círculo de giz caucasiano
}

Maurini de Souza Alves Pereira. E-mail: neert|@terra.com.br

Professora da UTFPR. Doutoranda em Letras pela UFPR.

Resumo: O objetivo deste estudo é demonstrar, por meio de atitudes apontadas no texto embasadas em textos teóricos sobre o assunto, que Azdak, o juiz da obra "O Círculo de Giz Caucasiano" peça de Bertolt Brecht, apresenta uma postura ética coerente, transformada em lei - representada por ele mesmo - no momento subseqüente, a qual é aplicada também coerentemente, apesar das aparentes contradições do personagem. Sendo que a ética apresentada era destoante da então defendida pelo poder estabelecido, o personagem pode ser considerado responsável pelo conflito ético apresentado na obra.

Palavras Chave: Bertolt Brecht, Círculo de Giz Caucasiano, Conflito ético, Ética e Lei.

\section{Abstract}

The objective of this study is to prove, with attitudes in text, based on theoretical texts, that Azdak, the judge of "Der kauksische Kreidekreis", Brecht's play, has a coherent Ethic position. The Ethic is transformed Law - what is represented back by himself. However he seems contradictory, his Law is coherent too. As a result of the difference between Azdak's Ethic and the local power Ethic, he is considered responsible by the Ethic Conflict of the story.

Keywords: Bertolt Brecht, The caucasian chalk circle, ethical conflict, ethic, law.

Este estudo procura demonstrar a ética apresentada pelo personagem juiz Azdak, da peça teatral O Círculo de Giz Caucasiano, de Bertolt Brecht, a transição dessa ética (ethos, costume) a lei (nómos), na "velha lenda chinesa" em questão, assim como mostrar que os atos do juiz não eram contraditórios, nem seus julgamentos "pela cara" (MB: 174[1]), mas seguiam a um caminho que the garante o status de "força criadora do conflito ético", apresentada por Pe. Henrique Vaz em

O ethos como lei é, verdadeiramente, a casa ou a morada da liberdade. Essa a experiência decisiva que está na origem da criação ocidental da sociedade política como espaço ético da soberania da lei. No início das Leis, Platão nos fala da educação em éthesi...nomikois, o que se pode traduzir, evocando Montesquieu, 'no espírito de excelentes leis'. A idéia do ordenamento ou constituição (politeia) do Estado segundo leis que nascem do ethos da comunidade fecha, assim, o círculo semântico do ethos, ao conferir à práxis sua mais alta qualificação, vem a ser, a da virtude política ou disposição permanente para o exercício da liberdade sob a soberania da lei justa" (VAZ, 1999, p. 16)

Para isso, será feita a apresentação da obra (O Círculo de giz caucasiano) e do Personagem (Azdak), abordando-o nas diversas facetas expostas no texto, para formar o que Wayne Booth chama de "conjunto de referências", necessário para que se possa

chegar ao "senso de valor", ao ser comparado a um "novo elemento" (BOOTH, 1988). 


\section{A peça}

A peça começa com o encontro, num vale do Cáucaso devastado pela Segunda Guerra Mundial, de duas comunidades, que pretendem recomeçar suas vidas após a destruição. Os antigos donos do local alegam que o vale é deles por tradição, e também foi utilizado de sua maneira desde o princípio: a lei diz que o vale é seu. A comunidade que deseja repartir esse espaço apresenta projetos e propostas para que o local seja mais bem aproveitado, alegando que a tradição deve ceder lugar ao bom uso e que as leis devem ser revistas. No final, os primeiros são convencidos e, para comemorar, um menestrel contará uma "antiga lenda chinesa", com "algumas modificações", para ilustrar a ação.

O "espaço compartilhado" (VAZ, 1999) é, portanto, o assunto que rege a história, da qual deriva a lenda. Esse significado do ethos se faz presente, metaforicamente, em todo o texto, representando as verdades transmitidas pela ficção:

\footnotetext{
Por tanto, una obra literaria de ficción puede ser verdadera incluso en el caso de no contener proposiciones verdaderas. Sus verdades son verdades que no están dichos en, sino mostradas por el texto; son verdades en las cuales los acontecimientos personas y cosas relatadas están en a relación de lo particular a lo general. La interpretación de una obra literaria de ficción ha de encontrar, pues, eso general indeterminado para un particular dado, que será la totalidad de los acontecimientos, personas y cosas relatados (SCHILDKNECHT, 1994, p. 66).
}

Como portadora de um ensino não proposicional, a peça reforça a teoria brechtiana de que o teatro deverá divertir, mas também ensinar. Brecht, nessa peça, sintetiza sua teoria e também sua prática na dramaturgia de textos representantes de um teatro dialético, que buscava transmitir verdades sem abrir mão do valor literário.

A peça dentro da peça trata do filho do governador, líder político local; único herdeiro dos bens, foi esquecido pela mãe na hora da fuga, decorrente de um golpe político que exterminara o marido. A revolta não foi popular, houve apenas troca de poder nas classes dominantes. O novo governante oferece uma quantia em dinheiro para quem matar o menino, o que leva os criados a se afastarem da criança, abandonando-a. Uma serva, porém, de nome Grusche, compadece-se dela, sendo atraída pela "terrível... tentação da bondade" e foge para a casa de seu irmão nas montanhas, carregando-a, sofrendo todo o tipo de perseguições e provações pela viagem. Na sua cidade de origem, havia noivado com um soldado, que foi para guerra, e a quem Grusche prometeu que esperaria. Mas o menino Michael precisava de um teto, e por isso, ela se casou (só no "papel"). Quando o soldado volta, descobre-a casada e com o menino, que julga ser filho da criada, e não espera explicações, abandonando-a. Nesse momento, guardas aparecem para levar Michael novamente a sua verdadeira mãe, pois houve outro golpe, os antigos voltaram ao poder e a mulher do Governador só poderia reaver seus bens se estivesse em posse da criança.

Começa, então, a segunda parte da história, que volta ao tempo da primeira 
revolta: "A história do juiz" ou Azdak. Escrivão da aldeia que, sem saber, acaba salvando a vida do Grão-duque, líder absoluto antes do primeiro golpe e que volta ao poder no segundo. Quando vai se entregar, numa autopunição por ter salvado a vida do antigo governante e certo de que prejudicara, de alguma forma, os "novos tempos", descobre que os tempos continuam os mesmos, e acaba sendo escolhido juiz.

Durante dois anos, julga o povo, sempre exigindo o dinheiro dos ricos, mas fazendo "vista grossa aos que nada tinham". Quando o antigo poder foi restabelecido, temeu por sua vida, mas, no momento em que iriam enforcá-lo, um mensageiro do Grão-duque traz uma mensagem dizendo que o juiz deveria continuar sendo ele, por ter salvo uma "vida particularmente preciosa para o país".

Inicia-se o julgamento para se decidir com quem deverá ficar a criança: com a mãe a cujo sangue pertence ou com quem a criou? No final, Azdak traça um círculo de giz no meio da sala e profere o julgamento salomônico: a criança deveria ser puxada pelas duas até que saísse do círculo. Grusche ficou com medo de machucar o menino, perdendo a disputa e ganhando a guarda, por ter sido considerada a verdadeira mãe. $A$ peça termina com uma festa, em que Azdak desaparece para nunca mais ser visto.

Uma das características importantes do texto é a inclusão de aforismos, um dos símbolos da tradição, do que se passou de geração em geração. Eles aparecem como quebra na ação, apontando para o hibridismo épico dramático da peça e serão apresentados na seqüência como uma das diferenças entre a lei aplicada e a ética apregoada no drama.

Enquanto Simon expõe os argumentos dos explorados nas relações sociais, os provérbios de Azdak defendem o pensamento dos dominantes, apesar das atitudes do juiz deixarem claro que ele não compactua com tal classe; as contradições entre os pensamentos dos dois, e a contradição entre a palavra e as ações de Azdak, com o objetivo de criar, no público, uma atitude revolucionária, são exemplos dos elementos contrapostos, que permeiam todo o texto, de personagens a enredo, e ilustram a afirmação de Brecht que, para ele, dialética se revela a partir da peça, e não ao contrário.

\section{A personagem}

Como característica da novela moderna, Maria Herrera Lima (1999, p. 54) apresenta "la pluralidad de voces narrativas (narrador y personajes que no coinciden necesariamente con la voz Del autor) que plantean contradicciones y ambigüedades de sentido y se abren a más de una interpretación posible". Entendendo que esse tratamento dialético é dado por Brecht à sua peça, e que o juiz Azdak é o que mais se destaca nas falas que "não coincidem necessariamente" com a voz do autor, mas que, justamente por essa contraposição e aparente ambigüidade, possibilita ao texto um estudo dialeticamente estruturado, esse personagem será foco nesta análise. 
O estudo dialético de Azdak é fundamental para demonstrar a antinomia éticalei representada pelo personagem da peça. No juiz, observa-se a transição da ética a uma nova nómos, que seria a síntese da contraposição inicial, isto é, o juiz criou uma nova lei, baseada na ética.

A história de Azdak, de escrivão a juiz, pode ser vista como conflito e comunhão entre a ética por ele apresentada e a lei estabelecida, tendo em vista o conceito de conflito ético como transgressão:

É talvez a idéia de transgressão que nos poderá conduzir mais diretamente à essência mais íntima do conflito ético, e completar com um último traço a fenomenologia do ethos. (...) A transgressão é pensada imediatamente em oposição ao tabu, ao interdito e à lei. Nesse sentido excludente, a transgressão se define como a ruptura dos limites impostos aos indivíduos com a sua identidade verdadeira e com a sua liberdade, rompidas as cadeias do ethos (VAZ, 1999, p. 33).

Mas para isso, deve-se estar disposto a aceitar as "exigências mais profundas e aparentemente paradoxais do ethos: o apelo a sacrificar o calmo reconhecimento dos limites e a segurança protetora das formas tradicionais desse mesmo ethos, e a lançarse no risco de um novo e mais radical caminho da liberdade" (IDEM, p. 34). É possível enquadrar o juiz nesse panorama, tanto na sua atitude de auto-entrega à morte, quando descobriu que salvara o Grão-duque, tanto quando se torna Lei e estabelece, durante os dois anos de juiz, a sua ética como nómos. No momento em que o antigo poder volta à tona, ele expressa medo, confessando que tinha consciência de que a sua lei era fruto de uma ética contrastante com a do governo estabelecido. Também esse medo é contraditório, pois quando a situação que temia se fez fato, e ele estava sendo espancado e conduzido à morte, chamou os soldados que o prenderam de "cachorros", serviçais e lambedores de botas, num ato de coragem ou inconseqüência.

Para melhor situar esse personagem tão controverso, ele será apresentado em sua construção, a partir da declaração de Brecht, também como personagem, sob a visão do "outro", antes de assumir o posto de juiz, e após assumi-lo, na análise de dois de seus julgamentos.

Azdak, pelo autor

Em seu Diário de Trabalho, Brecht confessa os problemas encontrados para criar um personagem que deveria ser dialeticamente convincente:

As dificuldades com a caracterização de Azdak me detiveram por duas semanas, até que encontrasse o fundamento social da sua conduta. No começo, tinha apenas sua legislação miserável, com a qual os pobres se davam bem. (...) Azdak tinha que ter traços egoístas, amorais e parasitários, tinha que ser o mais baixo e mais degenerado dos juízes. Mas ainda me faltava uma causa elementar de ordem social. Encontrei-o em sua decepção ao perceber que a queda dos velhos senhores não anuncia um novo tempo, mas um tempo de novos senhores. Assim, ele continua a praticar o direito burguês, só que esfarrapado, sabotado, no exclusivo interesse do próprio juiz, (...) essa explicação não muda nada das minhas intenções e não justifica Azdak (BRECHT, 2002, p. 200) 
O personagem extrapolou as intenções, e o que Brecht chamou de "veredictos descuidados" se apresentou como a antítese à lei estabelecida, gerando uma nova ordem, que durante os dois anos em que a peça se situa, possibilitou uma forma de justiça não concebida pela constituição vigente.

Azdak, pelo "outro"

Attridge (1999) apresenta o outro como "o outro ser humano", conforme o senso comum; “o próximo”, postura bíblica; o que restringe o nosso direito, na forma social; o estrangeiro, no âmbito cultural; e o colonizador ou colonizado, em termos políticos. Para qualificar Azdak, Brecht utilizou o olhar do "outro", e alguns personagens expressam a opinião sobre ele, parte presente na formação do conjunto de referências sobre o juiz, a fim de delimitar sua função dialética no texto:

Schalva: Eu sei que tens bom coração (...) És um homem superior, tu mesmo o dizes (...) É Azdak, nosso escrivão (...) Meus senhores, acredito que no fundo ele não é má pessoa. Uns furtozinhos de galinha e de vez em quando uma lebre, talvez (MB: 138, 140, 145)

Cozinheira: Não é um juiz como os outros, é o Azdak. É um odre de vinho e não entende nada de ofício. Os maiores ladrões foram absolvidos por ele. Como troca tudo e os ricos nunca lhe dão dinheiro bastante, os pobres como nós muitas vezes se saem bem com ele. (...) A madama te arrancaria os cabelos ser não soubesse que o velho Azdak é pelos humildes. Ele julga pela cara. (MB: 170,174)

Primeiro Advogado: Cara Natella Abaschvili, abstenha-se de toda investida, até que haja a certeza de que o Grão-duque nomeou novo juiz e que estamos livres do juiz presentemente em exercício, certamente o mais sórdido que já se viu vestir a toga de magistrado. (MB: 173)

Grusche: Sua esponja borracha (besoffene Zwiebel) (...) Tu te fizeste criado deles pra que não Ihes tomem as casas, porque elas foram roubadas; desde quando as casas pertencem aos percevejos? Mas tu vives de espionar, sem o que eles não podiam pegar homens para guerra, seu vendido! Não me metes medo mais que um ladrão ou um bandido com sua faca, ele (...) pra ocupações como a tua deviam escolher só violadores de crianças e agiotas como punição, para que eles sejam forçados a se fazer de respeitáveis aos olhos de seus semelhantes, o que é pior para eles do que espernear na corda de uma forca. (MB: 183,184)

Uma boa pessoa que rouba galinhas ou lebres, um juiz que nunca recebe o suficiente, mas é pelos humildes, um magistrado sórdido para a classe dominante, e um lacaio dos ricos, para a criada Grusche. Mesmo para o "outro", Azdak é múltiplo e contraditório, e nenhum personagem consegue concebê-lo em suas contradições, ou chegar a uma conclusão sobre a complexidade de suas atitudes: para a cozinheira, ele não entende do ofício, e absolve os "maiores ladröes", demonstrando que o povo estava consciente de que a lei era feita para proteger os poderosos, o que também se entende na fala de Grusche. Azdak não era entendido como antítese a essa lei pelos personagens, e suas atitudes não levam as pessoas da peça a uma síntese.

Que poderia estar, então, na posição do próprio personagem. Com a exposição de suas próprias características, o personagem contribui na complementação de informações textuais, ampliando o quadro de multiplicidade e contradição em que está envolvido e que rege a linha dialética do juiz. 
Azdak, por ele mesmo

Não tenho bom coração coisa nenhuma. Quantas vezes já te disse que sou um intelectual? (MB: 138).

Sou eu, o abjeto, o traidor, o marcado. Eu hospedei inadvertidamente o Grão-duque, ou melhor, o Grão- sacripanta (MB: 140).

É bom para a justiça funcionar ao ar livre. O vento lhe levanta a saia e pode-se ver o que está por baixo (MB: 157).

E tu, boa velha, e tu, santo homem, bebei um copo de vinho com o Promotor Público e com nosso amigo Azdak (MB: 164).

Schalva, os dias de teu cativeiro estão contados, talvez mesmo os minutos. Por longo tempo te mantive sob o freio de ferro da razão, que te pôs a boca em sangue, te espanquei a golpes de princípios racionais, te maltratei, com a lógica (MB: 165).

Eu costumava fazer vista grossa aos que nada tinham, isto vai me custar caro. (...) meti o nariz nos bolsos dos ricos, o que é considerado uma obscenidade (MB: 167)

Uma pessoa dócil, Excelência, que está disposta a servi-la (MB: 167).

Contam a meu respeito que um dia, antes de pronunciar a sentença, eu saí para respirar o cheiro de uma roseira (MB, 181).

Sou um homem sem instrução, visto calça furada debaixo da toga, olha só tu mesma. Comigo tudo se vai em comida e bebida, fui educado numa escola de convento (MB: 183).

Mais uma lista de contraditoriedades: um intelectual ("ein geistiger Mensch"), que utiliza a lógica e razão como armas, mas sem instrução, sensível e amigo dos pobres, apesar de dócil e serviçal aos poderosos. Consciente, porém, de que, para a sociedade em que vivia, era um criminoso (fora-da-lei). Sob diversas perspectivas, Azdak é envolto em contradições, e dessa forma ele pode personificar a antinomia ética-lei dentro de sua complexidade. A caracterização o apresenta como contraventor da lei estabelecida e portador de uma ética própria, popular, apesar de raramente reconhecida pelos demais personagens; a risada do ladrão Irakli, outro contraventor e também portador de uma ética popular, é uma das poucas atitudes que mostram um entendimento à ética do juiz.

Azdak, porém, é apresentado em dois momentos: como contraventor e como lei, já que, ao se tornar juiz, submeteu a almofada o código existente e fez de sua ética, a nova lei, isto é, a síntese do processo dialético apresentado.

\section{Azdak, escrivão da aldeia (contraventor)}

Considerando que a pessoa que não cumpre ou não se submete às leis é conhecida por "fora-da-lei", uma maneira de analisar Azdak nessa fase é como quem não se coloca dentro do domínio dessa lei. Tendo em vista que esse assunto se divida na questão da ética abranger todos os campos, independente do que seja certo ou errado (BOOTH, 1988), ou "não sendo o ethos senão a face da cultura que se volta para o horizonte do dever-ser ou do bem" (VAZ, 1999, p.19), essa abordagem não 
entrará no mérito do que foi certo ou errado, bom ou mal.

Azdak, o escrivão da aldeia, é um personagem que segue a "tradição ética", derivada de uma "Lei não-escrita, invocada por Antígona numa bem-conhecida passagem de Sófocles" (VAZ, 1999, p.17). A passagem citada é a seguinte:

Creonte: (...) sabias que fora proclamado um édito que proibia tal ação?

Antígona: Sabia. Como não havia de sabê-lo? Era público.

Creonte: E ousaste, então, tripudiar sobre estas leis?

Antígona: É que essas, não foi Zeus que as promulgou, nem a Justiça, que coabita com os deuses infernais, estabeleceu tais leis para os homens. $E$ eu entendi que os teus éditos não tinham tal poder, que um mortal pudesse sobrelevar os preceitos, não escritos, mas imutáveis dos deuses. Porque esses não são de agora, nem de ontem, mas vigoram sempre, e ninguém sabe quando surgiram. (SÓFOCLES, 1997, p. 45)

A idéia que remete a essa passagem é apoiada pela engraçada cena do quarto quadro de O Círculo de giz caucasiano, em que Azdak discute com o policial Schauva a respeito da lebre do Príncipe, que roubou para comer:

\begin{abstract}
Schauva (astuto): (...) se roubam uma lebre ao Príncipe, e eu sou da polícia, que devo fazer com o criminoso?

Azdak: Schauva, Schauva, devias ter vergonha! Tu te plantas na minha frente e me fazes uma pergunta, e não há nada que possa ser mais capcioso do que uma pergunta. Como se fosses uma mulher, uma Nunowna, por exemplo, uma perdida, e como Nunowna me mostraste tua coxa, perguntando-me: 'Que devo fazer com a minha coxa? Está me comichando'. Ela é tão inocente quanto parece? Não. Eu apanho uma lebre, mas tu apanhas um homem. Um homem é uma criatura feita à imagem de Deus; uma lebre não, sabes disso. Eu sou um comedor de lebre, mas tu és um comedor de homem, Schauva, e Deus nos julgará. Schauva, vai pra casa e penitencia-te... (MB: 138)
\end{abstract}

E Schauva foi. Pois essa “lei-não-escrita” de que o animal deve servir para alimentar o homem mais do que para divertir os príncipes faz parte da tradição do povo, mesmo que não faça da sua realidade. Ao defender o outro lado (a outra “ética”), o policial é comparado à que se prostitui para enredar os homens.

Para basear sua afirmação, Azdak utilizou-se da intertextualidade bíblica “Um homem é uma criatura feita à imagem de Deus", o que reafirma a teoria de que "a religião se apresente, em todas as culturas conhecidas, como a portadora privilegiada do ethos" (VAZ, 1999, p. 18). A Bíblia apresenta a história de quando os discípulos de Jesus, em um sábado, colheram espigas para se alimentar e foram acusados pelos fariseus de burlarem a lei; na ocasião, Jesus respondeu:

Nunca lestes o que fez Davi quando estava em necessidade e teve fome, ele e os que com ele estavam? Como entrou na casa de Deus, no tempo de Abiatar, sumo sacerdote, e comeu os pães da proposição, dos quais não era lícito comer senão aos sacerdotes, dando também aos que com ele estavam? Então lhes disse: O sábado foi feito por causa do homem, e não o homem por causa do sábado.[2]

Isto é, a lei ideal deveria servir ao homem, e não ao contrário. Essa idéia, retirada da ética popular que antecedeu as leis, é entremeada na história de Azdak, reafirmada pela ameaça de que "Deus nos julgará", demonstrando a superioridade da ética à lei estabelecida. 
Também a tradição da hospitalidade, tão presente nas culturas antigas, é preservada pelo escrivão, que não só acolhe e esconde o Grão-duque, sem saber de quem se trata, como também o alimenta, dá-lhe pouso e lhe ensina como se defender, mesmo depois de descobrir que ele não era alguém de sua classe: "Acaba de comer o teu queijo, mas come como um pobre, senão eles ainda te agarram. Será preciso que eu te ensine como procede um pobre?" (MB: 138). Esse trecho, que mostra a ênfase à tradição sem discorrer sobre ela no texto, é um exemplo profícuo do conhecimento não proposicional apresentado por Schildknecht (1999, p. 29):

El conocimiento no-proposicional, (...) Se muestra en la forma de un poder, de una capacidad o de una competencia en un contexto pragmático. No consiste precisamente en la formulación de un enunciado (verdadero o falso). Formas de este conocimiento práctico son, en Platón, la sabiduría de la experiencia y de la tradición.

Brecht não explica as atitudes de seu personagem, ele apresenta suas características, deixando ao público o julgamento. É também essa forma, "não proposicional", que rege o próximo traço que marca Azdak como contraventor.

O terceiro ponto enquanto escrivão "fora-da-lei" está localizado no momento em que ele se entrega (obrigou o policial a amarrá-lo e conduzi-lo aos soldados, invertendo a ordem pré-estabelecida e fazendo valer sua ética). Se o fez, foi porque acreditava que a revolução havia trazido "novos tempos", que a ética passaria a ser regente das novas leis, e nelas, um homem que salvou a vida do Grão-duque deveria morrer. Era seu "conhecimento intuitivo", outra forma não-proposicional:

El conocimiento ético, que descansa en esta forma de conocimiento no-proposicional, se manifiesta también de una manera no-proposicional: su adquisición es, según Platón, una cosa del esfuerzo y del dolor (...) El conocimiento ético se muestra en las consecuencias que tiene su adquisición para la propia dirección de la vida, en una postura ética, en una razón práctica, en una capacidad. (SCHILDKNECHT, 1994, p. 31)

Apesar de parecer uma atitude desmantelada e exagerada, fato de entregar-se aos couraceiros comprova a coerência entre os argumentos de Azdak e suas ações, assim como a veracidade nessa relação. A ética, para o escrivão, e posteriormente ao juiz, estava acima de seu bem estar, e somente por ela, ele seria capaz de entregar sua vida. Essa idéia se comprova com sua mudança de atitude ao descobrir que o poder havia apenas mudado de mãos, o que ficou claro quando os guardas contaram que haviam dizimado os tecelões. E foi justamente essa mudança de tática que o levou ao cargo de juiz, pois os couraceiros o escolheram por ele saber "tudo em matéria de direito", isto é, pelo seu conhecimento da lei, e não por sua ética.

Como juiz, ele não julgou baseando-se na lei existente, mas se tornou lei, aplicando-a segundo a sua própria ética, voltando à raiz das constituições. Lei, para Azdak, baseia-se na "etimologia de nomos (...), ou seja, repartir segundo a conveniência ou o uso. Daqui a origem de eunomia, repartir com justiça, ou segundo a razão da justiça, que se celebra como a propriedade essencial da lei." (VAZ, 1999, 16) 
Essa lei é a síntese dialética do conflito, e toda a caminhada de Azdak foi em direção a ela. Por isso, o próximo enfoque deste texto será

\title{
Azdak, a lei
}

A primeira indicação de que o juiz submeteu a lei anterior é o tratamento que dá à Constituição:

\begin{abstract}
Azdak: (...) Me traga aquele livro grosso, que eu sempre faço de almofada para sentar!. (Schauva apanha em cima da cadeira de Juiz um grande livro, que Azdak se põe a folhear.) Isto aqui é o Código das Leis, e você é testemunha de que eu sempre fiz uso dele.

Schauva: Pelo menos para sentar em cima. (GC: 278)
\end{abstract}

Nessa passagem, em que o humor se sobrepõe à dramática situação do juiz que está temendo ser enforcado, a metáfora do livro de leis sobre o qual se senta apresenta o relacionamento, nesses dois anos de magistrado, entre Azdak e a antiga lei: dominada, ela passou a servir para o que o juiz determinasse; submetida, ficava embaixo dele nos momentos dos veredictos. Nessa hora difícil, em que está prestes a perder o poder (após os dois anos, quando os antigos reassumem), busca o Código para tentar fazer as pazes, e se livrar de alguma maneira. O que sabe que não seria possível:

Pois eu costumava fazer vista grossa aos que nada tinham, isto vai me custar caro. (...) E não posso me esconder em parte alguma, porque todos me conhecem, pois a todos tenho ajudado... É o fim. Mas eu não darei a ninguém o prazer de mostrar grandeza da alma. (Para Schalva) Peço-te de joelhos que tenha dó de mim, não te vás embora, a saliva me corre da boca, tenho medo de morte. (MB: 167)

É o preço a pagar pelo conflito ético: "Pai, se possível, passa de mim este cálice", numa sociedade em que o poder estabelecido pune a transgressão. Brecht utiliza-se de uma metáfora para apresentar ao público a diferença entre a lei e a justiça, e também as conseqüências que esse embate pode trazer. E o uso dessa e de outras figuras de linguagem, na relação ética-literatura, remetem a Platão:

La metáfora, la ironía socrática y la aporía pertenecen a las formas de comunicación indirecta propias de los diálogos platónicos: estos no dan ninguna respuesta definitiva, sino que con su carácter aporético apuntan más allá de sí mismos persistiendo en la cuestión. El lectores reconducido hacia sí mismo a través de los pasajes metafóricos, aporéticos y vacíos de contenido, de los diálogos. Los procesos de formación del saber filosófico no son simplemente presentados en el diálogo, sino que contagian también al lector. (SCHILDKNECHT, 1994, p. 36)

As três figuras de linguagem apontadas estão presentes em O círculo de giz caucasiano; a metáfora do livro de leis, o tratamento irônico que Azdak reserva aos poderosos e a aporia do julgar melhor estando bêbado são apenas alguns exemplos dessa marca que permeia todo o texto.

Para mostrar como era aplicada a nova lei, a peça apresenta três julgamentos de Azdak, além do principal, referente ao círculo de giz. O terceiro é o melhor para 
exemplificar a postura do juiz enquanto lei.

Dois grandes proprietários de terra levam a juízo uma velha camponesa que mantinha uma vaca pertencente a um deles, e um presunto do outro. O segundo também reclamava que vacas dele haviam sido mortas para que deixasse de cobrar o arrendamento do lote da senhora. Ela atribui, tanto os bens quanto o perdão da dívida, à atuação de "São Banditus", que os proprietários acusam ser Irakli, cunhado dela, um justiceiro que roubava dos ricos para dar aos pobres. Esse personagem é o que mais se aproxima do juiz enquanto contraventor. Azdak multou os proprietários em "quinhentas piastras", por não acreditarem em milagre e absolveu a velha e o "São Banditus", a quem ofereceu vinho depois da sentença, precedida pela declaração lírica:

\footnotetext{
Azdak: Boa velha (Mutterchen), por pouco não te chamo mãe Geórgia, a dolorosa,

A esbulhada, cujos filhos estão na guerra,

A esmurrada, a que, cheia de esperanças,

Chora se ganha uma vaca,

Se admira se não é batida. Boa velha, te imploramos, os danados,

Que nos julgue com clemência! (MB: 163).
}

A ética da tradição, que respeita as velhas e viúvas, agora é Lei, e ao contrário de ser fruto da bebedeira ou da sordidez, como o julgamento de Azdak foi definido por outros personagens, essa lei decorre de uma "profunda filosofia":

Pues se necesita frecuentemente una profunda filosofía para restituir a nuestro sentimiento el primitivo estado de inocencia, para encontrarse a si mismo entre los escombros de cosas ajenas, para empezar a sentir por si mismo, hablar por si mismo, y casi quisiera decir también para existir una vez por si mismo. (SCHILDKNECHT, 1994, p. 39)

Essa "profunda filosofia" regeu também o julgamento principal, o do "círculo de giz". Para Azdak, estava bem claro que a criada Grusche não era a mãe verdadeira, assim como que a mulher do governador queria a criança para readquirir seus bens. Ele cobrou dos advogados da segunda, e liberou de pagamento a primeira, seguindo sua ética.

No meio do julgamento, uma disputa com Simon trouxe à tona os provérbios, outro vínculo com a tradição: “El camino y no el resultado de este pensamiento, el acompañar a alguien y no la teoría argumentativa (...) se encuentran también en el punto central de la forma: no la forma científica, cerrada y sistemática del tratado, sino la forma abierta y literaria del aforismo." (SCHILDKNECHT, 1994, p. 37)

O aforismo é um dos símbolos da tradição, da "sabedoria do povo", do que se passou de geração em geração. O personagem Simon, soldado, noivo de Grusche, é o que, desde o começo da peça, ilustra suas argumentações com esse símbolo. Durante o julgamento, após ouvir de Azdak que os pobres querem lei, mas não querem pagar ("Quando vão ao açougueiro, sabem que têm que pagar; mas quando procuram o Juiz, vão como quem vai para um velório"), Simon retruca:

Simon (em voz alta): 'Quando se ferra o cavalo, o carrapato estica as pernas', diz o ditado.

Azdak (aceitando a provocação, de bom grado): 'Mais vale uma jóia no estrume, do que uma pedra na água corrente'. 
Simon: 'bonito dia! Vamos pescar? Disse o anzol à minhoca'

Azdak: 'O dono de mim sou eu, disse o criado, e cortou o pé fora'.

Simon: 'Eu amo a vocês todos como um pai, falou aos camponeses o Czar, e o próprio filho mandou degolar'.

Azdak: 'O pior inimigo do idiota é ele mesmo.'

Simon: Mas 'o peido é assim porque não tem nariz. (GC: 290)

É uma cena em que ambos estão bem à vontade em seu universo da "lei-nãoescrita", da tradição popular. De uma conversa dessas, a governadora e seus advogados não participam, pois eles fazem parte de uma outra ética, são regidos por outras leis. Nessa tradição, porém, o sangue tem um valor sagrado: a família é constituída por pessoas do mesmo sangue - "filho de peixe, peixinho", "o filho da onça carrega a pinta", "a águia criada entre as galinhas é águia". O filho, pela tradição, deveria viver com sua mãe de sangue, que conforme os advogados "concebeu nos sagrados êxtases do amor, carregou-o no seu corpo, alimentou-o com o seu sangue, deu à luz com dores" (MB:. 177), e por isso, mesmo depois de tanto tempo, requer a criança. Esse é o motivo de tanta hesitação no veredicto do juiz. Mesmo assim, Azdak a entrega para a que the deu seu tempo, seus cuidados, a que gastou com ele o seu dinheiro, numa aparente quebra da lógica até aqui exposta por ele.

Mas esse fato, em vez de lhe tirar o caráter de "personalidade de ética excepcional", (VAZ, 1999, p. 30), vem complementar as características apontadas para o portador do "Conflito ético", da "transgressão":

Conquanto imanente ao movimento do ethos, a transgressão (...) dá, assim, testemunho desse ethos do qual prorrompe e, ao mesmo tempo, anuncia o advento de um novo mundo de valores. É nessa face positiva da transgressão que a força criadora do conflito ético se apresenta nítida e irresistível, descobrindo no seu fundo, a própria natureza do ethos. (IDEM, p. $34,35)$

Com a atitude tomada no julgamento final, Azdak consegue o "transbordamento" na ética que apregoou e viveu; ela revela a ética do autor, defensor de que a "coisa" pertence a quem cuidar bem dela. Nesse ponto, a personagem completa sua função dialética, ao mostrar o que Hegel denominou de "movimento", isto é, que mesmo o novo, como o caso da lei de Azdak, regida pelo ethos, a qualquer momento não estará mais nessa posição, será ultrapassado por algo mais novo ainda, numa constante modificação.

Azdak apresenta-se, portanto, como uma força criadora do conflito ético, por algumas características, tais como as posturas tomadas desde o início de seu aparecimento no texto, sempre voltado a defender e agir dentro de uma ética própria e diferente da apresentada pelo poder constituído, mesmo que essa ação acarretasse dano próprio, como no caso em que se entregou à guarda por ter escondido o Grãoduque. Ao se tornar juiz, transformou essa Ética (ethos) em Lei (nómos), como síntese dialética da questão. Regeu seus julgamentos dentro da tradição popular, submeteu a antiga lei à "almofada" para sentar-se e trouxe à tona o verdadeiro sentido do nómos, 
"repartir segundo a conveniência ou o uso", e eunomia, "repartir com justiça, ou segundo a razão da justiça". Julgando aparentemente de forma incoerente o caso da criança, buscou, além de seguir a tradição de proceder sabiamente (copiando Salomão e a antiga tradição oriental) anunciar "o advento de um novo mundo de valores". Por isso que, dialeticamente falando, esse personagem é bem estruturado.

Vaz apresenta que Sócrates, Jesus Cristo e Buda, como regedores de conflito ético, conquistaram seguidores, pessoas que trocaram seus conceitos éticos pelos desses líderes (VAZ, 1999, p. 31); no caso de Azdak, porém, os "seguidores" não aparecem, pois o juiz não conseguiu quem o entendesse no texto. A solução para esse impasse está no comentário de Habermas (1990, p. 242) de que “O texto pode engolir não somente o autor, mas também a diferença categorial entre ficção e realidade, no momento em que torna transparente em si mesma a operação de produção de um novo mundo." Como Azdak conseguiu superar até mesmo as expectativas de seu autor no que diz respeito aos julgamentos que promulgou, essa ficção tinha em vista, como todo o trabalho brechtiano, um mundo em transformação, e isso faz com que se atribua ao público o possível seguidor de Azdak, como regedor de uma lei baseada na ética popular.

\section{Referências Bibliográficas:}

ATTRIDGE, D. Innovation, Literature and Ethics. Relating to the Other. 1999

Bíblia de Referência Thompson. Trad. J. F. de Almeida. SP: Vida. Florida, 1992.

BOOTH, W. The Company we Keep. An Ethics of Fiction, Chicago, 1988

BRECHT, B. Diário de Trabalho - vol. 1 - 1938-1941. Rocco, RJ, 2002.

. O Círculo de Giz Caucasiano. Trad. M. Bandeira. São Paulo: Cosac \& Naify, 2002. - Trad.: G. de Campos. Rio de Janeiro: Paz e Terra, 1992.

HABERMAS, J. Pensamento Pós-Metafísico - Estudos Filosóficos. Rio de Janeiro: Tempo Brasileiro, 1990.

LIMA. M. H. “El punto de vista moral em la literatura”. In: LOPES DE LA VIEJA, M. T. Figuras Del logos. Entre la Filosofia y la Literatura. México: Fonte de Cultura Económica, 1994.

SCHILDKNECHT, C. Formas literárias de la filosofia. In: LOPES DE LA VIEJA, M. T. Figuras del logos: entre la filosofia y la literatura. México: Fuente de Cultura Econômica, 1994.

SÓFOCLES. Antígona. Versão do grego: M. H. da R. Pereira. Brasília: UnB, 1997.

VAZ, H. C.de L. Escritos de Filosofia II - Ética e Cultura. São Paulo: Loyola, 1999.

[1] A peça em foco será apresentada em duas traduções: a de Manuel Bandeira, em BRECHT, Bertolt. O Círculo de Giz Caucasiano. Trad. Manuel Bandeira. São Paulo: Cosac \& Naify, 2002; e a de Geir de Campos, Trad. Geir de Campos. Rio de Janeiro: Paz e Terra, 1992, que serão tratadas, doravante, por (MB: número da página) e (GC: número da página), respectivamente. 
[2] BíBLIA, Português. Bíblia Sagrada: de referência Thompson. Trad. João Ferreira de Almeida. São Paulo: Vida, 1992. Ev. de Marcos. Cap. 2, vers. 23-27. 